\title{
CONHECIMENTOS OCEANOGRÁFICOS NA COMUNIDADE TRADICIONAL Barra do Ararapira
}

\author{
Ana Paula Rainho ${ }^{*}$ \\ ${ }^{1}$ Doutoranda em Antropologia pela Universidade Federal de Santa Catarina \\ *Autor para correspondência: anap.rainho@gmail.com \\ Recebido em 03 de agosto de 2016. Aceito em 30 de março de 2018. Publicado em 14 de abril de 2018.
}

\begin{abstract}
Resumo - Este trabalho teve como objetivo compreender a complexidade dos conhecimentos oceanográficos dos moradores da comunidade Barra do Ararapira, localizada dentro do Parque Nacional de Superagui (Guaraqueçaba PR). Os moradores mostraram que possuem conhecimento sobre as dinâmicas físicas, sedimentares, meteorológicas e biológicas do oceano e da região costeira. Tais conhecimentos são adquiridos através da prática pesqueira, mas não se limitam somente a esta, pois é construído em todas as etapas da vida dos moradores. As crianças são iniciadas a tais saberes por parentes próximos e pelos membros mais velhos da comunidade. Enquanto os adultos continuam a ampliar seus conhecimentos a partir da observação diária do oceano e dos debates constantes entre os moradores. Entretanto, toda essa complexidade dos conhecimentos dos moradores é ignorada pela gestão do Parque Nacional de Superagui, que inviabilizou a participação da comunidade na construção do plano de manejo. Os moradores desejam participar ativamente do plano de manejo através de seus complexos conhecimentos que englobam o entendimento sobre ambientes tão diferentes, como o céu, o mar e a terra, para que assim, possam decidir sobre o futuro de seu território e de suas próprias vidas.
\end{abstract}

Palavras-chaves: Conhecimento Tradicional; Pescadores Artes anais; Comunidade Tradicional.

\section{OCEANOGRAPHIC KNOWLEDGE IN THE TRADITIONAL COMMUNITY OF BARRA Do ARARAPIRA}

Abstract - The aim of this study was to understand the complexity of the oceanographic knowledge of the residents of the Barra do Ararapira community, located within the National Park of Superagui (Guaraqueçaba - PR). The residents have shown that they have knowledge about the physical, sedimentary, meteorological and biological dynamics of the ocean and the coastal region. Such knowledge is acquired through practice fishing, but is not only limited to this, it is being constructed at all stages of the residents' lives. Close relatives and the older members of the community initiate children in such knowledge. The adults continue to expand their knowledge by observation of the ocean and through the constant debates among the residents. However, all this complexity of residents' knowledge is ignored by the Superagui National Park management, which made it impossible for the community to participate in the construction of the management plan. The residents want to actively participate in the management plan with their complex knowledge, which embodies the understanding of different environments such as the sky, the sea and the land, so they could be able to decide about the future of their territory and their own lives.

Keywords: Traditional KNOWLEDGE; ARTIS ANAL Fishers; Traditional COMMUNITIES.

\section{Conocimientos oceanográficos En la comunidad tradicional Barra do Ararapira}

RESUMEN - Este trabajo tuvo como objetivo comprender la complejidad de los conocimientos oceanográficos de los moradores de la comunidad Barra do Ararapira, ubicada dentro del Parque Nacional de Superagui (Guaraqueçaba -PR). Los residentes mostraron que tienen conocimiento de las dinámicas físicas, sedimentarias, meteorológicas y biológica 
del océano y de la región costera. Tales conocimientos se adquieren por medio de la práctica de la pesca, pero no se limitan sólo a esto, pues se construyen en todas las etapas de la vida de los residentes. Los niños se inician en tales saberes por familiares cercanos y por los miembros mayores de la comunidad. Mientras tanto, los adultos siguen ampliando su conocimiento por medio de la observación diaria del océano y de los debates constantes entre los residentes. Sin embargo, toda esa complejidad de los conocimientos de los habitantes es ignorada por la gestión del Parque Nacional de Superagui, que inviabilizó la participación de la comunidad en la construcción del plan de manejo. Los residentes desean participar activamente del plan de manejo a través de sus complejos conocimientos que engloban entornos tan diferentes como el cielo, el mar y la tierra, para que así puedan decidir sobre el futuro de su territorio y de sus propias vidas.

Palabras clave: Conocimiento Tradicional; Pescadores Artesanales; Comunidad Tradicionales.

\section{INTRODUÇÃO}

A comunidade tradicional caiçara conhecida como Barra do Ararapira, localizada dentro do território considerado Parque Nacional de Superagui (Guaraqueçaba - PR), apresenta conhecimentos complexos acerca do oceano. Conhecimentos que não se limitam a uma espécie específica e nem mesmo se reduz somente a dimensão marinha, mas um saber que se estende para outros espaços, englobando terra, mar e céu, de maneira integrada, formando um conhecimento que tem como base uma noção tridimensionada do espaço (Cunha 2007). Pois:

Para existir como pescador, é preciso se afirmar na fruição dos seus sentidos concretamente, em seu dia-a-dia, nos diálogos que realiza com o mar, através de sua atividade produtiva. $\mathrm{O}$ mar e os pescados colocam componentes complexos a serem compreendidos, tanto para ter sucesso na pescaria, quanto para obter segurança, por isso, para ser pescador é preciso desenvolver um saber especializado (Ramalho 2011).

Para ter sucesso na pescaria é preciso conhecimento sobre o aspecto reprodutivo, a cadeia trófica, o comportamento e a relação com o vento, maré e correntes de cada espécie pescada. Para obter segurança em mar é necessário ter conhecimento sobre o assoalho oceânico para não encalhar o barco, saber sobre vento, maré, correntes, ondas e até prever o tempo para não serem pegos desprevenidos por uma tempestade em alto mar. Apesar da complexidade de seus conhecimentos, as comunidades caiçaras são na maioria das vezes excluídas dos processos de gestão ambiental e políticas pesqueiras. A comunidade tradicional Barra do Ararapira também se encaixa nessa problemática, pois seus conhecimentos são ignorados pela gestão do Parque Nacional de Superagui (PNS), que atualmente se encontra em processo de construção do plano de manejo.

Apesar de ter sido criado em 1989 (Decreto n. 97.688, de 25 de abril de 1989), o Parque não possui regularização fundiária e nem plano de manejo. A construção deste iniciou-se em 2012 com a contratação de apenas três funcionários e com o objetivo de terminá-lo até o final de 2013, porém as datas não foram atendidas (Duarte 2013). De acordo com a autora, os documentos iniciais resultantes da tentativa de um plano de manejo geraram descontentamento por parte das comunidades tradicionais que afirmavam que o processo não estava sendo participativo e que as poucas reuniões que os gestores do ICMBio realizaram foram distorcidas para encaixar os objetivos conservacionistas entre as supostas demandas dos moradores. A preocupação dos gestores não era ouvir e nem incluir as comunidades, mas sim, em apenas notificá-las das possíveis novas regras do parque que seriam definidas pelo plano de manejo. Os documentos iniciais do plano de manejo também parecem ocultar as comunidades afetadas e a diversidade cultural dos moradores da Ilha de Superagui, pois 
se levou em consideração apenas nove comunidades, das vinte atingidas pela gestão do PNS (Parecer Técnico $\left.2013^{1}\right)$. De acordo com Duarte (2013), as comunidades caiçaras anseiam por participação ativa na construção do plano de manejo para que possam deliberar sobre o futuro do Parque.

Nós queremos o que com esse encontro? Que realmente esse tal de plano de manejo, tem que sair né. Não saiu em 25 anos e querem fazer em 3 meses. Nós pedimos que se tiver que sair que saia, mas queremos, nos pescadores, participação nele profunda. Didi, morador da comunidade de Tibicanga, localizada no PNS. Fala durante o Encontro sobre a "Violação dos Direitos Humanos provocados pelos Parques Nacionais em territórios de comunidades tradicionais caiçaras", no dia 06/12/2013.

Não há motivos para negar a participação das comunidades na construção do plano de manejo do Parque, ainda mais quando elas se mostram tão interessadas em participar. A participação seria uma questão básica de direitos humanos, presente na OIT 169, artigo $6^{\circ}$, que afirma que os povos tradicionais devem ser consultados das medidas legislativas ou administrativas que os afetem diretamente. Além disso, os ecossistemas marinhos e costeiros são altamente complexos (Berkes et al. 2001) e possuem muitos detalhes desconhecidos pela ciência ocidental, mas que são contemplados pelo empirismo diário das comunidades tradicionais que sobrevivem por meio da interação que desenvolveram nos ambientes marinhos e terrestres (Pereira e Diegues 2010). Para os autores, estes conhecimentos trazem importantes contribuições para a compreensão do funcionamento destes sistemas complexos e, por conseguinte, para melhorias na administração e proteção das unidades de conservação. De acordo com Diegues et al. (1999; 2000), torna-se necessário resgatar os sistemas tradicionais de manejo, resultante da complexidade dos conhecimentos das comunidades tradicionais e indígenas, pois essas técnicas têm contribuído significativamente para a manutenção da diversidade biológica. Para o autor, as comunidades tradicionais não somente devem ser ouvidas, como devem dispor de poder deliberativo nos órgãos de decisão, o que infelizmente, raramente acontece em países como o nosso, sendo o caso do Parque Nacional de Superagui, apenas um entre vários que ocorrem no território brasileiro.

Kalikoski (2006) afirma que o conhecimento dos (as) pescadores (as) artesanais demonstrou conter princípios de preservação de caráter fundamental para a sustentabilidade da atividade pesqueira artesanal e tem se mostrado de grande importância na avaliação da atual gestão pesqueira do estuário da Lagoa dos Patos, devendo ser considerados tanto na reestruturação da legislação vigente, como na criação de novas formas de manejo. Os conhecimentos dos pescadores (as) também podem ser aplicados no manejo do ambiente terrestre, já que apresentam conhecimentos botânicos, como mostrado por Hanazaki (2002), Miranda e Hanazaki (2007) e Peroni et al., (2008), além de conhecimentos zoológicos e geológicos, como mostrado por Rainho, (2015). Toda essa abrangência de conhecimento poderia vir a somar na construção de uma gestão adequada, coerente com a realidade local da Ilha de Superagui e que seja socialmente justa, possibilitando que as comunidades gerem não somente o Parque, mas também suas próprias vidas.

\section{Material e métodos}

1 O parecer técnico foi feito por pesquisadores (as) de diferentes áreas do Instituto Federal do Paraná (Paranaguá) e da Universidade Federal do Paraná (Curitiba e Matinhos) a pedido das comunidades para que estes avaliassem os documentos iniciais do plano de manejo.

2 Encontro organizado pelo Movimento dos Pescadores Artesanais (MOPEAR) e pelo Movimento dos Pescadores e das Pescadoras Artesanais do Brasil (MPP) com o objetivo de contestar os documentos iniciais do plano de manejo. 
A etnografia foi a metodologia utilizada neste trabalho. De acordo com Sáez (2013), outros cientistas têm o laboratório, o arquivo ou a biblioteca, já os antropólogos têm o campo, isto é, qualquer lugar onde acontece, vive ou vive-se aquilo que ele (ou ela) quer estudar. A etnografia seria nada mais que uma vivência plena, intensa e cotidiana na comunidade ou qualquer outro lugar que será o objeto de estudo de uma determinada pesquisa. Para Sáez (2013), a etnografia é uma operação muito mais complexa que a observação participante, que as entrevistas ou mesmo os diálogos entre o antropólogo e a comunidade estudada. Sua complexidade se deve a essa vivência no campo, que se diferencia das entrevistas por não se limitar a apenas alguns dias e horas com a comunidade estudada, mas sim, possibilitar o contato com a comunidade todos os dias e em todas as horas. Por se tratar de uma vivência, a etnografia não possui uma metodologia fechada ou um manual de passo a passo, pois o (a) pesquisador (a) passa a viver na comunidade estudada e para viver em um determinado lugar não existe uma forma metodológica de como se fazer isso. A partir disso, esta pesquisa foi feita com base numa etnografia de três meses na comunidade tradicional Barra do Ararapira durante o inverno de 2014, com uma vivência que permitiu compartilhar dias, noites, almoços, jantares, pescarias, beneficiamento do pescado, melhoramento de apetrecho de pesca, entre outros momentos riquíssimos que resultou em uma dissertação de mestrado e neste artigo científico.

\section{RESUltados E DiscusSÃo}

Comunidades caiçaras possuem um detalhado conhecimento sobre os ambientes que ocupam e exploram (Allut 2000, Hanazaki 2002). Os (as) pescadores (as) apresentam conhecimentos ictiológicos, como nos mostra Marques (1991); Begozzi e Figueiredo (1995); Fernandes-Pinto (2001); Ramires e Barella (2001); Clauzet et al. (2005), Ramires et al. (2007). Na comunidade Barra do Superagui (localizada no entorno do Parque Nacional de Superagui), os pescadores e pescadoras apresentam um conhecimento refinado e detalhado sobre os hábitos alimentares e das interações tróficas entre diferentes grupos de organismos, elaborando cadeias tróficas em até seis níveis (Fernandes-Pinto 2001). As comunidades caiçaras também possuem conhecimentos físicos e atmosféricos, assim como conhecem as dinâmicas de interação entre atmosfera e o oceano como nos mostra Cunha (2007) e Moura (2009). Os pescadores e pescadoras de Pontal do Paraná (litoral paranaense) revelaram deter conhecimento sobre os tipos de ventos, de marés e acerca da posição da lua (Cunha 2007). De acordo com a autora, os (as) pescadores (as) associam as espécies com os movimentos das marés, dos ventos e dos astros para assim obter sucesso na pescaria.

\footnotetext{
Desse modo, o conhecimento, além de estar ligado a um savoir-faire, como um ter jeito, relaciona-se com uma rede conceitual de conhecimentos espaciais e ambientais tão ou mais essenciais que na cultura manual ou técnica. Tudo isso surge de um processo que pressupõe um sujeito cognitivo em constante interação entre o trabalho mental e manual, e entre este e seu entorno (Allut 2000).
}

Na comunidade Barra do Ararapira também foi verificado um amplo conhecimento sobre cada uma dessas áreas, além de observado um conhecimento geológico sobre as dinâmicas sedimentares que ocorrem na região. A base de seus conhecimentos está ancorada em saberes atmosféricos e como estes afetam as espécies e as dinâmicas marinhas e costeiras, pois os conhecimentos mais comentados eram constantemente associados com o sentido e intensidade do vento. A condição do vento se mostrou ser um saber essencial para se acessar outros 
saberes. $\mathrm{O}$ vento mais comentando foi o vento sul que, de acordo com a comunidade ${ }^{3}$, caracteriza-se por ser um vento que traz o frio, chuvas, tempestades, aumenta a maré e as ondas. É um vento marítimo forte que traz o frio de regiões mais temperadas e polares. Já o vento leste e nordeste trazem sol e muito peixe, além de deixar a maré mais baixa. O aumento da maré a partir do vento sul e a diminuição pelo vento nordeste também foi documentada por Moura (2009), em sua pesquisa sobre os pescadores artesanais da Lagoa dos Patos.

O vento leste e nordeste possuem também certas características que os tornam mais adequados para a atividade pesqueira, relação também observada entre as comunidades caiçaras pesquisadas por Cunha (2007). Estes ventos deixam a água mais suja, com mais nutrientes advindos de rios e lagos, permitindo um aumento das espécies marinhas que buscam por alimento, além de reduzir a visibilidade do peixe, permitindo que estes sejam capturados mais facilmente. Atraem peixes como manjuba, que são comidio ${ }^{4}$ dos peixes maiores. $\mathrm{O}$ vento norte tem um efeito semelhante aos ventos leste e nordeste. A diferença é que o vento norte traz temperaturas mais altas. $\mathrm{O}$ vento sudoeste, oeste e noroeste são ventos que vêm do continente. Tais ventos retiram o peixe que se encontra próximo da região costeira e o leva para alto mar, sendo ruim para as pescarias próximas à costa.

O vento é muito dinâmico, num mesmo dia, ele pode mudar de direção, transformando de um vento para outro. O vento sul, por exemplo, pode começar de manhã, mas com o passar das horas pode mudar até virar vento sudeste. No período da tarde o vento já mudou novamente, virando vento leste. De noite, o vento para por um instante até virar vento oeste. No dia seguinte, amanhece com vento sudoeste. Essa transformação do vento, que os moradores denominam de viração, não ocorre todo dia da mesma maneira. Algumas vezes um vento determinado pode durar muitas horas, o dia todo ou até dias consecutivos. Vento longo e forte mexe com o mar, traz muita chuva e aguaceiro, aumenta as ondas e a correnteza no sentido em que o vento está puxando, inviabilizando a pescaria.

O vento nordeste quando dura até o dia seguinte é denominado briseiro. O vento nordeste é um vento bom para as pescarias, mas apenas quando começa entre as onze horas da manhã e dura até às seis horas da tarde. Entretanto, caso tal vento persista até o outro dia, os moradores da Barra do Ararapira já sabem que o tempo vai ficar ruim, porque esse vento vai durar por três dias, permanecendo forte e intenso. O briseiro geralmente ocorre poucas vezes por ano. Acontece no verão, mas algumas vezes também chega a ocorrer nos meses de abril e maio.

As correntes marítimas seguem um comportamento semelhante. A corrente leste (também denominada de corrente norte ou água do norte que vai para o sul $)^{5}$ é a melhor para a pescaria porque suja a água com plâncton e traz o peixe do mar para a costa, principalmente quando esta corrente está associada ao vento leste. Quando um vento específico venta por dias acaba influenciando a direção da corrente marítima, mas isso é válido apenas para ventos duradouros e intensos, pois a corrente geralmente atua no sentindo contrário do vento. Já a corrente sul (ou água do sul que vai para o norte/leste) espanta o peixe, sendo boa apenas para a vinda da tainha.

A maré também é muito importante para a atividade pesqueira. Apesar de definida pela atividade gravitacional da lua, também sofre grande influência dos ventos atmosféricos. A maré de lua é a maré ocorrida na lua cheia e na lua nova, enquanto a maré de quarto ocorre na lua minguante e na crescente. A maré de lua é a

3 Todo o conhecimento sobre os oceanos citados neste artigo são conhecimentos pertencentes à comunidade Barra do Ararapira.

4 Comidio é como os nativos chamam os peixes que são alimentos de outros peixes, como a manjuba.

5 Os moradores raramente chamam de corrente, é mais costumeiro chamar de água do norte ou água que vem do sul para norte/ leste para referir-se à corrente sul. E água do sul ou água do norte/leste que vai para o sul para referir-se à corrente norte/leste. Os moradores também chamam leste de norte e vice-versa quando se referem às correntes. 
que mais impacta o oceano, é quando a maré é mais intensa, com os períodos de maré alta apresentando as maiores marés. Enquanto na lua cheia a maré cresce mais no período da noite, na lua nova a maré cresce mais de dia. A combinação de lua cheia (ou nova) com vento sul cria as maiores marés, fato também documentado por Cunha (2007). Já maré de quarto é mais fraca que maré de lua. Entretanto, se for maré de lua e vento nordeste, vento responsável por decrescer a maré, a maré fica baixa. E se for maré de quarto com vento sul, a maré aumenta muito de tamanho, possibilitando uma maré mais intensa do que em dias de lua cheia (maré de lua) com vento nordeste. Por conta da forte influência do vento sul durante o inverno, esta é a estação do ano em que as marés ficam maiores.

A lua trabalha muito com a terra, com a plantação, a pescaria e até gravidez de mulher. Lua nova é mais forte que a cheia. Rebojo com lua nova e cheia faz a maré crescer muito. Maré de lua sem vento sul não cresce tanto. O vento sul, sudeste são os responsáveis pelas maiores marés. Não existe mês de maio e abril que a maré não cresce. Rubens, entrevista dia $16 / 04 / 2014$

Devido aos efeitos da maré é essencial saber quando a maré está enchendo e quando está vazando, tanto para o ofício de pescador quanto para ser morador da Barra do Ararapira. Existem várias maneiras de se descobrir, a mais simples é através da observação da posição do barco ancorado na praia. Se a popa da canoa (parte de trás da embarcação) estiver apontando para o norte a maré está enchendo. Se a popa estiver apontando para o sul a maré está vazando. Entretanto, observar a situação da maré considerando a posição da popa do barco não é muito confiável, devido ao efeito do vento, que pode mudar a embarcação de direção sem estar necessariamente relacionado com o funcionamento da maré. Uma forma mais confiável de compreender os horários da maré é através da observação da lua que funciona como um relógio, principalmente na época de lua cheia. Quando a lua cheia nasce, a maré está sempre vazando. Quando a lua cheia está bem no meio do céu, a maré começa a encher. Quando a lua se põe, a maré começa a vazar. Apesar disso, os horários da maré são diferentes a cada dia, pois o nascer da lua atrasa, geralmente, uma hora de um dia para o outro. Esse atraso da lua também foi relatado pelos pescadores (as) da Lagoa dos Patos, de acordo com Moura (2009). No primeiro dia de lua cheia, a lua nasce às dezoito horas. No segundo dia às dezenove horas e assim por diante, até mudar de lua. Por isso, a maré atrasa e a cada dia a maré terá horário diferenciado.

A maré também sofre variações de horário a partir do sentido do vento. Durante vento sul a maré vaza mais tarde, e durante vento leste a maré vaza mais cedo. Em vento leste, a variação do atraso da maré, de um dia para o outro, também é menor. Em vez de uma hora de atraso, a maré vai se atrasar apenas vinte minutos. Esse tipo de conhecimento não é mais tão comum como era antigamente. De acordo com Rubens, os antigos moradores da Barra do Ararapira sabiam tudo sobre maré apenas observando o céu. Atualmente, os moradores se guiam através da observação da maré num dado momento e, a partir disso, calculam os próximos horários que a maré irá encher ou vazar. Isso ocorre porque a maré será exatamente igual após doze horas, como mostra Santiro:

Cada dia muda, cada dia a maré tem uma diferença. Às vezes amanhece e está enchendo, às vezes está enchendo às nove horas da manhã. Varia de dia. Mas a gente consegue prever com umas doze horas de antecedência, porque se às dezoito horas estiver enchendo, significa que amanhã às seis horas da manhã vai estar enchendo também. Santiro, entrevista dia $16 / 04 / 2014$.

Os moradores da Barra do Ararapira também possuem amplo conhecimento sobre as espécies marinhas.

6 Rebojo é a denominação nativa para vento sul com chuva. 
Das espécies marinhas que capturam, conhecem o comportamento, a mobilidade, a reprodução e a cadeia alimentar. Esses conhecimentos não são iguais para todos. Algumas respostas variaram muito, principalmente quando referente a espécies específicas que não são tão importantes para a atividade pesqueira da comunidade. As espécies mais conhecidas, como sororoca (nomenclatura nativa para o peixe cavala), tainha e robalo, são também as espécies mais pescadas.

Sororoca gosta de água fria, vem do sul. Robalão gosta de tempo quente, no inverno volta para o rio. Ele gosta de ficar nos sedimentos, debaixo dos galhos. Come peixinho e filho de peixe. Irineu Pires, entrevista dia 15/04/2014.

A tainha é uma espécie muito bem conhecida por toda a comunidade. De acordo com os moradores, a tainha é um peixe de corrida, pois se desloca do Rio Grande Sul para as regiões mais ao norte do Brasil. A corrida da tainha é percebida por pescadores e pescadoras de outras regiões do país, como os pescadores da Lagoa dos Patos (Moura 2009) e da Juréia (Ramires Souza e Barrella 2001). Para que as tainhas percorram o trajeto de sua corrida é necessário a ação do vento sul, relação também observada pelos (as) pescadores (as) de Pontal do Paraná (Cunha 2007). Porém, não é apenas o vento sul que as trazem para as regiões mais quentes da costa brasileira, mas uma combinação específica de ventos. Primeiro o vento sul precisa soprar por uns dois dias até ser capaz de influenciar a corrente. Depois que a tainha chega até o estado do Paraná, para ela se aproximar da região costeira e atravessar a desembocadura em frente à comunidade, é necessário a força do vento nordeste.

O robalo também é um peixe de corrida, mas é uma espécie mais influenciada pela salinidade da água do que pela ação do vento, já que é uma espécie que vive tanto em água doce quanto em água salgada, apesar de preferir mais a água doce dos rios. Por isso, quanto maior a predominância e intensidade das chuvas, mais o robalo irá se deslocar em direção ao oceano. De acordo com os moradores, o robalo também costuma se deslocar de um rio até o outro.

Mês de outubro chove muito aqui. E o pessoal torce para chover. Chuva dá robalo. Nesse mês a água aqui fica preta que nem água do rio. Quanto mais suja a água mais o robalo vêm. Eles vão para o mar fažer a corrida do peixe. Flávio, anotação de campo dia 13/07/2014.

Os moradores também conhecem a reprodução da tainha e do robalo. A reprodução da tainha começa com as fêmeas criando suas ovas na escama. O macho esfrega-se no corpo da fêmea até conseguir fecundar as ovas. Depois, a fêmea carrega os juvenis na escama para proteger dos outros peixes e só solta quando se sente segura. O robalo se reproduz de uma forma diferente, já que é um peixe que se reproduz no rio. De acordo com a pescadora Valmira, o robalo procura um galho no fundo do rio para depositar as ovas. Ao encontrar, bate sua nadadeira caudal sobre o galho até formar um buraco, local onde a fêmea irá soltar os óvulos para que o macho, posteriormente, deposite seu esperma. Ambos os peixes, macho e fêmea, ficam tomando conta das ovas fecundadas até eclodirem os juvenis.

O linguado é também um peixe que os moradores apresentam conhecimento sobre, apesar de não ser uma espécie tão pescada, mas, ainda sim, é um peixe que apresenta muito valor para a comunidade devido ao seu tamanho, sabor e valor comercial. Na fala abaixo é possível perceber como o conhecimento sobre as espécies é amplo e está sempre relacionado aos conhecimentos sobre a maré e sobre o clima.

Peixe que dá no inverno também é o linguado. Ele deixa a forma dele na praia quando ele dorme. Quando a maré baixa é possivel ver seu formato na areia, chamamos de cama do linguado. Ele só dorme na maré cheia, não importa se é dia ou noite. Às vezes acontece dele dormir demais, a maré baixar e ele ficar na praia. É um peixe que só fisga em lua nova, ele vem de fora para dentro para se alimentar. É o unico peixe que tem os dois olhos para cima. Ele desova no mar, no inverno, come peixinho e marisco. Dico, entrevista dia 26/04/2014. 
Os moradores também conhecem o comportamento das espécies devido à observação diária do mar. Esse tipo de conhecimento é muito importante, pois os ajudam na localização do pesqueiro e na captura do cardume. Entretanto, isso é válido apenas para peixes boieiros, ou seja, para peixes que se alimentam e se deslocam pela superfície da água. Peixes que vivem junto ao sedimento, no fundo oceânico, não se comportam da mesma maneira, limitando sua compreensão pela dificuldade em avistá-los da embarcação. O peixe boieiro possui distintos comportamentos em água: piririca, quando o cardume acompanha os movimentos da onda do mar; relampeia, quando o peixe vira de barriga para cima na superfície d'água; pisca, quando um peixe muito pequeno vira de barriga para cima, semelhante ao comportamento de relampear, salta, quando o peixe pula para fora d'água; espana, quando o peixe coloca o rabo para fora d'água e o balança; galhando, quando o peixe fica com a pontinha da nadadeira fora d'água; urra, quando o cardume sobe para comer peixes menores que se encontram em cima, fazendo um barulho parecido ao de urrar. A relação entre espécie e comportamento pode ser visualizada na Tabela 1.

A manjuba pisca, o parati e a tainha fazem piririca, que é quando faz uma onda do cardume. Por serem peixes boieiros, eles acompanham a onda, então você vê aquela onda de peixe. A da tainha é bem maior que a do parati. O parati, a tainha, a manjuba, a sororoca, a salteira também relampeiam. Quando a água está bem clara é possivel ver um brilho saindo da água, que é quando o peixe vira de barriga para cima. Mário e Sebastião, entrevista dia 29/04/2014.

Tabela 1 - Conhecimento tradicional referente ao comportamento e à fisionomia de espécies marinhas.

\begin{tabular}{lcccc}
\hline Peixe & Tecido & Dentes & Comportamento & Fundo ou boia \\
\hline Tainha & Escamas & Não & $\begin{array}{c}\text { Salta, piririca, relampeia, } \\
\text { urra, galhando }\end{array}$ & Boieiro \\
Parati & Escamas & Não & Espana, piririca, relampeia, & Boieiro \\
Robalo & Escamas & Não & urra, galhando & Falhando \\
Manjuba & Escamas & Não & Pisca, relampeia & Boieiro \\
Linguado & Escamas & Sim & Piririca & Fundo \\
Sororoca & Couro & Sim & Relampeia, salta, urra & Boieiro \\
Anchova & Escama & Não & Piririca, urra & Fundo \\
Sardinha & Escama & Não & Piririca, urra & Boieiro \\
Peixe espada & Couro & Sim & Relampeia & Boieiro \\
\hline
\end{tabular}

Os moradores classificam os peixes a partir da sua posição na coluna d'água. O robalo, o linguado e a anchova são considerados peixes de fundo, pois se alimentam, dormem, e permanecem grande parte do seu tempo no fundo do mar. Porém, algumas vezes, estas espécies de peixes vão para a superfície d'água, comportando-se como um peixe boieiro, peixes que permanecem mais tempo na superfície do mar. Geralmente, o deslocamento pela coluna d'água está relacionado às etapas reprodutivas do peixe. Os moradores não sabiam informar exatamente o porquê de isso acontecer, mas, geralmente, encontram tais peixes na superfície nos períodos anteriores à desova. Os (as) pescadores (as) artesanais de algumas comunidades do litoral paulista também percebem um comportamento móvel do peixe pela coluna d'água devido a processos reprodutivos, de acordo com a pesquisa de Ramires et al. (2006). Marques (1991) e Clauzet et al. (2005) também notaram que os (as) pescadores (as) classificam os peixes a partir da distribuição na coluna d'água.

O inverso também é válido para certas espécies de peixe, como a sororoca e a corvina, que apesar de 
consideradas peixes boieiros podem ser encontradas no fundo do mar em determinados períodos. De acordo com os moradores, esse comportamento varia de acordo com a lua. Isso porque a lua influência no aumento ou na diminuição da ardentia, categoria nativa para fitoplâncton que apresenta bioluminescência. Quanto mais ardentia no mar, mais claro e visível tornam-se os peixes, pois cada movimento é iluminado pelo brilho da ardentia, transformando os peixes em presas fáceis. O aparecimento da ardentia geralmente ocorre na lua nova, no final da lua minguante e no começo da lua crescente. Prefere aparecer em noites escuras, água salgada, épocas menos chuvosas, e permanecer mais distante das desembocaduras dos rios. Como estratégia de defesa, os peixes ficam ariscos, categoria nativa para peixes que escapam rapidamente das redes, fazendo com que tais espécies se escondam no fundo do mar durante a época de ardentia. Tornar-se arisco é uma estratégia de defesa, que vai desde a busca por um esconderijo, para a velocidade que se adquire escapando das redes, até o comportamento da espécie que irá variar conforme o tamanho do cardume.

Quando o cardume está grande o peixe fica manso, quando o cardume está pequeno, o peixe fica arisco. Betão, anotações de campo dia 22/04/2014.

Algumas espécies como a anchova, o parati, a sororoca e a tainha assombram quando estão ariscas, elas flutuam e afundam rapidamente, desaparecendo da superfície do mar como uma estratégia de defesa com o objetivo de assustar seus predadores. De acordo com os moradores, cada animal tem uma forma de se proteger: a sororoca tem dentes, a tainha tem nadadeiras, o siri as garras, o bagre tem esporos, a moréia tem veneno. O cardume também atua como uma estratégia de defesa do grupo, agindo de diferentes maneiras: assustando e dispersando as presas ou sacrificando alguns indivíduos para salvar outros, com o objetivo de proteger o futuro da espécie.

Algumas sororocas se sacrificam para salvar outras, eu já tinha ouvido falar, mas hoje eu pude ver. Elas nadavam para o fundo da rede, até a rede afundar bastante a ponto das sororocas de cima conseguirem escapar. Flávio, anotações de campo dia 18/07/2014.

Além de todos esses conhecimentos, os (as) pescadores (as) precisam saber como prever o tempo, pois uma tempestade pode surgir quando estiverem em alto mar, colocando a vida desses homens e mulheres em risco. Preveem o tempo através:

\footnotetext{
...da direção das nuvens, se elas se movem vindo do sul, é vento sul que traz chuva e frio. Se as nuvens se movem do norte para cá, é calor, vento norte é quente. Maria Creuza, entrevista dia 17/04/2014.

...do mar, o mar anuncia um dia antes. Você olha a água e se ela está puxando para o norte é porque vem tempo do sul, sul é sempre frio. A tempestade dá pra saber pela água, ela vem com o tempo sul. O mar pressente, ele puxa antes. Santiro, entrevista dia 17/04/2014.
}

Fala semelhante ao de Santiro é encontrada entre os (as) pescadores (as) artesanais da Lagoa dos Patos, como nos mostra Moura (2009) em sua pesquisa. Allut (2000) também observou que os (as) pescadores (as) fazem estimativa da situação atmosférica a partir da observação do céu. De acordo com os moradores da Barra do Ararapira, o mais importante na previsão do tempo local é identificar quando o tempo está ameaçado, pois é um tempo caracterizado por forte vento norte e clima muito quente que pode se alterar a qualquer instante e, com isso, trazer tempestades perigosas. Isso ocorre quando o vento norte atua por mais de dois dias na região, transformando-se em um vento sul muito intenso devido à própria viração que o vento realiza. $\mathrm{O}$ tempo ameaçado serve como um alerta para o período em que os (as) pescadores (as) podem ou não pescar. Mesmo com todos esses conhecimentos, os moradores da Barra do Ararapira ainda podem ser pegos desprevenidos por uma 
tempestade em alto mar, mesmo quando o clima aparenta estar em ótimas condições. Por isso, quando vão pescar ficam sempre observando o céu na direção sul, pois quando forma um cinturão de nuvem ao sul, já sabem que vem tempestade. Cunha (2007) também menciona a importância de prever o tempo e identificar tempestades entre os (as) pescadores (as) de Pontal do Paraná. De acordo com a autora, a previsão das tempestades ocorre exatamente pela direção do vento conjugado aos demais fenômenos naturais, assim como pela observação da cor do céu e da presença de nuvens escurecidas, raios e trovões.

Outra maneira dos moradores perceberem quando virá vento sul é através da observação do comportamento das espécies. Espécie como a raia jamanta costuma pular quando está para vir vento sul. E quando muitas aves marinhas estão voando sobre a comunidade, os moradores já sabem que é sinal de chuva. De acordo com Allut (2000), só um conhecimento meticuloso dos fatores da dinâmica meteorológica sobre os aspectos relacionados com a pesca permite ao pescador ter um certo controle sobre o meio, de modo que, até certo ponto, fazer previsões, resaltando a complexidade dos conhecimentos caiçaras.

Todos esses conhecimentos são muito importantes para a pescaria. A pesca produz, reproduz e aprofunda os conhecimentos marinhos, mas não é a única forma de produção do conhecimento. No caso da comunidade estudada até sua localização geográfica impõe aos moradores uma necessidade de se adquirir profundos conhecimentos dos processos geológicos e físicos que acontecem na região costeira. A comunidade está localizada na frente de uma desembocadura que constantemente altera a geologia da região. Tais mudanças determinam a própria dinâmica territorial da comunidade, pois a força das marés, correntes e ondas que atravessam a desembocadura foi responsável por gerar, durante anos, erosões no território da comunidade. Muitos moradores precisaram mudar suas casas de lugar ${ }^{7}$ (às vezes construir outras) mais de três vezes por conta das constantes erosões. Durante este processo foi necessário um conhecimento sobre a disposição dos sedimentos: Aonde erode? Por que erode? Aonde essa areia é depositada? Todas essas são perguntas que os moradores acabam fazendo antes de começar a construir uma nova casa. Para entender sobre erosão, não basta saber sobre sedimento, mas também de toda a saída e entrada de água na desembocadura entre a Ilha de Superagui (PR) e a Ilha do Cardoso (SP), assim como os fatores que atenuam a força d'água. Isso mostra que só saber não é suficiente para compreender, mas que é preciso correlacionar causa e efeito, criando hipóteses para as dinâmicas geológicas costeiras e assim, tentar prever seu comportamento para escolher um lugar apropriado para se morar.

Os moradores sabem quais dinâmicas acarretam a erosão, correlacionando seus conhecimentos sobre geologia com conhecimentos sobre física marinha e climatologia. Sabem que determinados ventos (como o vento sul) e determinada marés (como a maré de lua) intensificam este processo, podendo prever as épocas mais intensas de erosão. Sabem que a areia retirada da parte sul da comunidade sedimenta mais ao norte, próximo a comunidade Pontal do Leste (Ilha do Cardoso - SP), depositando também na comunidade Marujá (comunidade da Ilha do Cardoso - SP, localizada na região norte da ilha). Com tanto conhecimentos sobre as dinâmicas sedimentares conseguem prever as mudanças que acontecerão em ambas as ilhas. De acordo com o morador Rubens, a desembocadura pode fechar. Isso pode acontecer caso outra desembocadura se abra na altura da Enseada da Baleia, comunidade localizada na parte sul da Ilha do Cardoso (SP), entre Pontal do Leste e Marujá.

7 A maioria das casas da comunidade é feita de madeira, o que facilita o transporte da casa de uma localidade para outra. 
Se a barra vai fechar? Se a enseada da baleia abrir, a barra fecha pela dinâmica do lugar e tudo vai mudar. O Mar do Varadouro e de Cananeia sai pela barra. Se mudar vai sair pela Enseada da Baleia e vai parar de erodir aqui e vai comesar a erodir o Cardoso. Rubens, entrevista dia 17/04/2013.

Tais saberes mostram a profundidade dos conhecimentos geológicos dos moradores que chegam a criar até hipóteses que estão sujeitas a experimentos. Para conter a erosão, os moradores fizeram diversos experimentos, como plantar árvores com raízes grossas, depositar areia e até colocar placas de contenção. Hipóteses também são formuladas para localizar o pesqueiro, pois a pesca da Barra do Ararapira é voltada para as espécies de peixes que se deslocam muito rapidamente pelo oceano, mudando sua localização constantemente. Para localizar tais cardumes, todos os conhecimentos sobre o mar são necessários. Por isso, os moradores se reúnem em grupos para debater, refletir e filosofar sobre o oceano. Muitas vezes os (as) pescadores (as) trazem observações empíricas sobre o dia (como as condições do vento, da corrente marinha, da lua, da maré, etc.) para comparar e coligar, num processo de causa e efeito, as informações que possuem a fim de descobrir a localização exata do cardume no dia seguinte. E mesmo os fracassos nas pescarias são utilizados na formulação de hipóteses e em momentos de reflexões para compreender o comportamento do peixe em seu ecossistema. A pesca não é apenas uma atividade prática, mas também é uma atividade intelectual, pois o (a) pescador (a) necessita refletir, e refletir muito, sobre diversos aspectos do oceano em seu cotidiano. De acordo com Lévi-Strauss (1976), um conhecimento desenvolvido tão sistematicamente, com tanta riqueza e precisão, não se limita a ordem prática, mas corresponde às exigências intelectuais de introduzir um princípio de ordem no universo, correspondendo a uma curiosidade intelectual.

A água está muito clara. Água clara é ruim para pescar, deixa o peixe arisco, ele consegue avistar a rede. E a água está clara porque faz dias que não venta leste. Flávio, anotação de campo dia 02/07/2014, fala após o cardume ter rapidamente escapado da rede.

E como todo esse conhecimento é de fato aprendido? Ao reparar nos conhecimentos das crianças da comunidade Barra do Ararapira, percebe-se que todas sabem alguma coisa sobre o mar. A relação com o oceano começa cedo, juntamente com as brincadeiras infantis. Entre as brincadeiras preferidas estão a pesca de linha, a natação e a observação do mar. Mesmo as brincadeiras que não têm relação direta com o oceano são realizadas à beira-mar. As crianças também acompanham seus pais na pesca. Desde cedo já são introduzidas na prática pesqueira e enquanto acompanham a pescaria, aprendem cada dia um pouco mais, tanto pela própria prática empírica do trabalho pesqueiro como através dos ensinamentos que recebem a bordo por seus familiares. Independente do sexo, todas as crianças ajudam os pais nas pescarias realizadas em frente à comunidade. Tanto as crianças quanto os adultos afirmam que seus conhecimentos sobre o oceano são adquiridos desde a infância, através da observação e dos ensinamentos dos moradores mais velhos.

A gente aprende vendo os mais velhos faz̧endo. Felipe, filho de 14 anos de Edina e Dico, anotação de campo dia $20 / 06 / 2014$.

Papai me ensina a lançar, a remar e a fazer rede. Sei um pouco sobre vento e maré. David, filho de 12 anos de Shirlei e Delmiro, anotação de campo dia 20/06/2014.

Aprendemos com todo mundo daqui, todo mundo fala sobre isso, todo mundo te ensina. Flávio, anotação de campo dia 15/04/2014

De acordo com Ramires et al. (2007), o conhecimento sobre a pesca em particular e toda a cultura caiçara

8 Nomenclatura nativa para desembocadura. 
em geral é transmitido através de experiências do cotidiano e através do relacionamento entre os membros das comunidades. Nas falas acima percebe como a relação entre os moradores produz e reproduz saberes, mas, como posto por Ramires et al. (2007), a produção do saber também passa pelas experiências do cotidiano, passa pelo empirismo diário que os (as) pescadores (as) estabelecem com o ambiente marinho. A pesca traz esse exercício à tona, pois permite que os (as) pescadores (as) se encontrem em contato direto com o oceano. Esse contato acontece não apenas porque se está no meio do oceano, mas também porque é necessário observar o mar constante e atentamente para capturar o pescado.

Eles localizam o cardume porque conseguem ver o cardume de manjuba saindo da água, alguns pulam, outros põem para fora parte do corpo, e é assim que localizam, porque a sororoca está debaixo da manjuba. Osnir, anotação de campo dia 13/04/2014.

Além da atividade pesqueira, os moradores da Barra do Ararapira possuem um diferencial importante que os ajudam a desenvolver conhecimentos sobre o mar: a forma como estão distribuídas as casas da comunidade. A grande maioria das casas são de frente para o mar, assim como a escola, a igreja, o campo de futebol e o galpão da igreja onde ocorrem os bailes, bingos e cursos. Esta distribuição das moradias obriga os moradores a olharem o mar em todos os momentos de suas vidas. Os casamentos são à beira-mar, assim como as festas de aniversário, as missas, as brincadeiras das crianças, o jogo de futebol dos adultos, etc. Cercados de água por todos os lados, os moradores não se limitam apenas a viver próximos do mar, mas a viverem dentro dele.

A gente vive dentro do mar. Onde quer que vamos estamos cercados de mar. É mar por tudo. A única saída para qualquer lugar é o mar. Vemos o mar toda hora, todo dia. E ainda tem o barulho do mar a noite para dormir. Flávio, entrevista dia $24 / 07 / 2014$

De acordo com Ingold (2000), alguns aspectos da natureza só podem ser aprendidos diretamente. O que pode ser muito bem observado na Barra do Ararapira, pois a oportunidade de se morar de frente para o mar e de trabalhar no meio do oceano não apenas amplia o trabalho empírico como os coloca em uma posição privilegiada de constante observação, ampliando as chances de avistar fenômenos naturais difíceis de serem vistos e mesmo compreendidos. Todo esse empirismo permite que os moradores conheçam os sons do vento, do mar e da fauna local, assim como o cheiro. Eles também sentem no tato os fenômenos naturais, quando pegam as espécies em suas mãos ou quando sentem o vento e a água em seus corpos. Essa percepção sensorial da comunidade amplia o conhecimento a todos os sentidos, pois os moradores passam a aprender olhando, escutando, cheirando e sentindo a natureza. Dona Iolanda, antiga pescadora da Barra do Ararapira, conta que aprendeu sobre vento quando era criança através de seus parentes, mas hoje, com anos de experiência, ela sente o vento na pele e já sabe sua direção.

Pescador sabe se vai estar bom para pescar só ouvindo o barulho do vento de noite, sabe de onde vem o vento e para onde vai. Betão, anotação de campo dia 25/04/2014.

A observação do mar, realizada pelos moradores da Barra do Ararapira, não está limitada apenas às pescarias e por uma questão espacial das moradias, mas está enraizada em uma questão cultural da própria comunidade. Quando os moradores estão nervosos, eles vão se acalmar olhando o mar. Espiar o mar (usando a categoria dos próprios moradores) é mais do que remédio para tristeza e angústia, mas também uma forma de lazer compartilhado entre todos os membros da comunidade, independente do sexo e da idade. Grande parte dos moradores passa muitos minutos (às vezes horas) dos seus dias olhando o mar, algumas vezes em grupo, 
outras vezes sozinhos, apenas pelo simples prazer de olhá-lo.

Antes eu espiava tanto o mar que ficava até com dor na nuca. Leontina, anotação de campo dia 02/07/2014.

A observação constante do mar permite que os moradores conheçam o oceano a partir de todas as suas dimensões. Isso inclui a coluna d'água, a superfície e o fundo oceânico, como também o céu (principalmente quando usam a lua e o vento como referência para diversos efeitos marinhos). A visão torna-se cíclica, completando um grande círculo de dimensões a sua volta que compreende os espaços terra-mar-céu (Cunha 2007), que é complementada com a utilização de todos os outros sentidos.

Outro fator que amplia o processo de aprendizado é a constância das conversas acerca do mar, sendo assunto de conversas diárias que os envolvem em todas as esferas de suas vidas. Eles falam, pensam, refletem, filosofam sobre o mar, confirmando e reafirmando seus conhecimentos o tempo todo. Diferente da sociedade urbano/industrial que separa as esferas da vida, definindo isso é conhecimento, isso é comida, isso é lazer; para os moradores da Barra do Ararapira está tudo junto: o mar gera comida, é conhecimento, é trabalho, é lazer. Nas rodas de conversa, o mar é um assunto tão corriqueiro que as piadas são formuladas utilizando conhecimento marinho. Isso mostra que não é apenas a pesca que gera saberes, mas sim toda a dinâmica cultural da comunidade que o produz. Saberes que são produzidos, compartilhados, discutidos, debatidos e ampliados a cada instante, bastando apenas estar na comunidade Barra do Ararapira para poder acessar a riqueza e complexidade de tais conhecimentos oceanográficos.

É só ter um grupo de homens reunidos que o assunto é mar, pode ter certez̧a. Rosi, entrevista dia 17/04/2015.

\section{Conclusão}

Os conhecimentos oceanográficos dos moradores da Barra do Ararapira são desenvolvidos através da prática pesqueira, do contato constante com o mar, da localização geográfica da comunidade, dos diálogos, debates e reflexões entre os moradores e através do amor e admiração que nutrem pelo oceano. De acordo com Marques (1991), os (as) pescadores (as) possuem e partilham um modelo percebido do seu ambiente, o qual inclui tanto aspectos temporais quanto espaciais, dimensões que para os (as) pescadores (as) não estão separadas, mas que se entrelaçam. Os moradores conhecem e descrevem as diversas dimensões que compõem seu território, assim como conhecem a interação entre uma e outra. Eles também conhecem a interação entre os componentes bióticos e abióticos do oceano, apresentando conhecimentos biológicos, físicos, geológicos e meteorológicos.

O conhecimento dos moradores é ao mesmo tempo racional e sensorial, teórico e prático. É também empírico, tridimensional, intelectual e cultural. Apresentam um conhecimento descritivo e classificatório, mas também apresentam um conhecimento de causa e efeito, em que hipóteses são criadas e até testadas. É um conhecimento que possui valor, pois são estes conhecimentos que sustentam a comunidade, já que para viver na Barra do Ararapira é preciso toda uma gama de saberes. Tais saberes são necessários para subsistência, para geração de renda, para sobrevivência em mar, para apropriar-se de seu próprio território e até para ser bem visto na comunidade. Os maiores conhecedores (geralmente homens e mulheres mais velhos) são admirados e bem vistos, procurados pelos mais jovens quando estes têm dúvidas sobre a maré ou para debater o porquê do peixe 
se deslocar para um lado e não para o outro. O conhecimento dos moradores da Barra do Ararapira é mais do que um simples saber, mas o porta-voz da cultura local.

Apesar de todos esses aspectos dos conhecimentos apresentados neste artigo, os moradores da Barra do Ararapira são excluídos do processo de construção do plano de manejo do Parque Nacional de Superagui. Para Allut (2000), os (as) pescadores (as) são os que melhor conhecem o entorno ecológico e social de cada uma das comunidades, porém quem planifica as políticas pesqueiras e a gestão dos recursos são os funcionários, com a assessoria de biólogos e economistas. De acordo com Cunha (2007), há diversos estudos sobre os conhecimentos caiçaras, seja para configurar sua importância em si, seja para apontar práticas de manejo daí emergentes, seja para contribuir na construção de novas formas de gestão socioambiental. Assim, não se trata de falta de conhecimento, pois os pescadores e pescadoras da Barra do Ararapira possuem um saber muito amplo e abrangente que viria a contribuir e muito na construção do plano de manejo. A questão vai além de quem detêm mais conhecimento, pois, mais do que uma mera disputa pelo saber, é uma relação de poder, em que aqueles com mais poder são os manejadores da natureza. Por isso, mais que mostrar a complexidade dos conhecimentos locais, é necessário que estes conhecimentos sejam ouvidos e levados em consideração nas definições de políticas pesqueiras e planos de manejo, assim como as demandas das comunidades afetadas.

A gente sabe prever o tempo, a gente sabe quando a água está boa para peixe. Eles não têm o conbecimento que a gente tem. A gente sabe por experiência. A forca verde considera a gente bandido. Não temos voz, não temos autoridade nem para pegarmos nossas redes de volta. Era pra sermos aliados deles e não inimigos. Edivaldo, entrevista dia 11/07/2014.

\section{REFERÊNCIAS}

Allut AG. 2000. O conhecimento dos especialistas e seu papel no desenho de novas políticas pesqueiras. In: Diegues AC (Org.), Etnoconservação: novos rumos para a conservação da natureza, São Paulo: Hucitec/ NUPAUB-USP, p. 101-123.

Berkes F, Mahon R, Mcconney P, Pollnac R, Pomeroy R. 2001. Managing small-scale fisheries: alternative directions and methods, Otawa: International Development Research Center, 285 p.

Brasil. Decreto n. 97.688, de 25 de abril de 1989. Cria o Parque Nacional do Superagui.

Clauzet M, Ramires M, Barrella W. 2005. Pesca artesanal e conhecimento local de duas populações caiçaras (Enseada do Mar Virado e Barra do Una) no litoral de São Paulo, Brasil. A Linguagem da Ciência, 4:1-22.

Cunha LH. 2007. Ordens e desordens socioambientais saberes tradicionais em dinâmicas pesqueiras da costa paranaense. Tese (Doutorado em Meio Ambiente e Desenvolvimento), Universidade Federal do Paraná, $206 \mathrm{p}$.

Diegues AC, Arruda RSV, Silva VCF, Figols FAB, Andrade D. 1999. Os Saberes Tradicionais e a Biodiversidade no Brasil. In: Diegues AC (Org.), Biodiversidade e comunidades tradicionais no Brasil, São Paulo: NUPAUBUSP, p. 1-117.

Diegues AC. 2000. A etnoconservação da natureza: enfoques alternativos. In: Diegues, AC (Org.). 
Etnoconservação: novos rumos para a proteção da natureza nos trópicos. São Paulo: Hucitec/NUPAUBUSP, p 1-46.

Duarte LA. 2013. Argonautas do Superagui: identidade, território e conflito em um parque nacional brasileiro. Dissertação (mestrado em Planejamento Territorial e Desenvolvimento Socioambiental), Universidade do Estado de Santa Catarina, 211 p.

Duarte LA, Barbosa AM, Dallagnol AH, Katuta AM, Antunes DAM, Garcia de Faria G, Gómez JR, Vandresen JC, Coelho K, Isaguirre KR, Varella MC, Rocha O, Martins P, Martins de Souza R, Castagnara V. 2013. Parecer técnico sobre os estudos preliminares encomendados para a elaboração do plano de manejo do Parque Nacional de Superagui - Guaraqueçaba - PR, 26 p.

Fernandes-Pinto E. 2001. Etnoictiologia dos pescadores da Barra de Superagüi, Guaraqueçaba/PR: aspectos etnotaxinômicos, etnoecológicos e utilitários. Dissertação (Mestrado em Ecologia), Universidade de São Carlos, 156 p.

Hanazaki N.2002. Comunidades, conservaçãoe manejo: o papel do conhecimento ecológicolocal. Biotemas, 16(1): $23-47$.

Kalikoski DC, Rocha RD, Vasconcellos MC. 2006. Importância do conhecimento ecológico tradicional na gestão da pesca artesanal no estuário da lagoa dos patos, extremo sul do Brasil. Ambiente \& Educação, 11: 87-118.

Ingold T. 2000. Hunting and gathering as ways of perceiving the environment. In: The perception of the environment: essays on livelihood, dwelling and skill, London: Psychology Press, p. 41- 60.

Lévi-strauss C. 1976. A ciência do concreto. In: O pensamento selvagem. São Paulo: Papirus, p. 15-50.

Marques JGW. 1991. Aspectos ecologicos na etnoictiologia dos pescadores do complexo estuarinolagunar Mandau-Manguaba. Tese (doutorado em Ecologia), Universidade Estadual de Campinas, 293 p.

Miranda TM, Hanazaki N. 2008. Conhecimento e uso de recursos vegetais de restinga por comunidades das ilhas do Cardoso (SP) e de Santa Catarina (SC), Brasil. Acta Botanica Brasílica, 22(1), 203-215.

Moura GGM. 2009. Águas da Coréia: pescadores, espaço e tempo na construção de um território de pesca na Lagoa dos Patos (RS) numa perspectiva etnooceanográfica. Dissertação (mestrado em Ciência Ambiental), Universidade de São Paulo, 250 p.

Pereira BE, Diegues AC. 2010. Conhecimento de populações tradicionais como possibilidade de conservação da natureza: uma reflexão sobre a perspectiva da etnoconservação. Desenvolvimento e Meio Ambiente, 22: $37-50$.

Peroni N, Begossi A, Hanazaki N. 2008. Artisanal fishers ethnobotany: from plant diversity use to agrobiodiversity management. Environment, development and sustainability, 10(5):623-637.

Rainho AP. 2015. A gente vive no mar: saberes oceanográficos na comunidade tradicional Barra da Ararapira. Dissertação (mestrado em Antropologia Social). Universidade Federal do Paraná, 171 p. 
Ramalho CWN. 2011. O sentir dos sentidos dos pescadores artesanais. Revista de Antropologia, 54 (1): $315-$ 352.

Ramires M, Barrella W. 2001. Conhecimento popular sobre peixes numa comunidade caiçara da Estação Ecológica de Juréia-Itatins/SP. Boletim do Instituto de Pesca, , 27(2):123-130.

Ramires M, Molina SMG, Hanazaki N. 2007. Etnoecologia caiçara: o conhecimento dos pescadores artesanais sobre aspectos ecológicos da pesca. Biotemas, 20(1):101-113.

Sáez OC. 2013. Etnografia: O campo. In: Esse obscuro objeto da pesquisa: um manual de métodos, técnicas e teses em Antropologia. Ilha de Santa Catarina: Edição do autor, p. 133-170. 